\title{
The effects of changing angle and height of toilet seat on movements and ground reaction forces in the feet during sit-to-stand
}

\author{
Su-Kyoung Lee', Sang-Yeol Lee,** \\ 'Department of Physical Therapy, College of Nursing and Healthcare Science, Dong-Eui University, Busan, Korea \\ ${ }^{2}$ Department of Physical Therapy, College of Science, Kyungsung University, Busan, Korea
}

The study aimed to examine the effects of changes in the angle and height on movements and ground reaction forces in the feet. Subjects were instructed to sit and stand on different angles and heights; $0^{\circ}$ ( 43 $\mathrm{cm}), 10^{\circ}(51 \mathrm{~cm})$, and $15^{\circ}(58 \mathrm{~cm})$. The motion required in this study is similar to that of standing up from sitting on a chair. The Tumble Forms Wedges $\left(10^{\circ}[8 \mathrm{~cm}], 15^{\circ}[15 \mathrm{~cm}]\right)$ were placed on the toilet seat to create angles and heights at $0^{\circ}(43 \mathrm{~cm}), 10^{\circ}(51 \mathrm{~cm})$, and $15^{\circ}(58 \mathrm{~cm})$. The side-to-side travel distances when the subjects stood up from sitting were $103.70 \pm 12.46$ at $0^{\circ}(43 \mathrm{~cm}), 96.99 \pm 12.11$ at $10^{\circ}(51 \mathrm{~cm})$, and $99.12 \pm 12.00$ at $15^{\circ}(58 \mathrm{~cm})$. The forward and backward travel distances when the subjects stood up from sitting were $235.93 \pm 10.60$ at $0^{\circ}(43$ $\mathrm{cm}), 194.17 \pm 8.07$ at $10^{\circ}(51 \mathrm{~cm})$, and $181.63 \pm 8.66$ at $15^{\circ}(58 \mathrm{~cm})$. The ground reaction forces when the subjects stood up from sitting were $1.09 \pm 0.02$ at $0^{\circ}(43 \mathrm{~cm}), 1.08 \pm 0.22$ at $10^{\circ}(51 \mathrm{~cm})$, and $1.07 \pm 0.21$ at $15^{\circ}(58$ $\mathrm{cm})$. Increases in the angle and height of the toilet seat affected forward-and-backward swaying during standing up, but did not affect the ground reaction force and side-to-side swaying.

Keywords: Ground reaction forces, Sit to stand, Toilet seat

\section{INTRODUCTION}

Standing up from a sitting position is frequently performed in daily activities, such as switching to a different position, walking, turning and climbing stairs (Hwang et al., 2008). While this movement appears simple, it requires complex interactions between the central nervous system and the neuromuscular system (Pai and Rogers, 1991), and emphasises the coordination and pattern of the body's segmental movements in which horizontal movements are shifted to vertical movements to maintain the balance of the centre of gravity on a narrow base of support (Barthelemy et al., 2006). Among the elements that disturb the motion of standing up from sitting, the height of the chair has the most critical influence (Scholz et al., 2001). In particular, around $42 \%$ to $43 \%$ of elderly people have difficulty standing up from a chair (Chamberlain and Munton, 1984). Compared to young adults, el- derly people perform the motion of standing up by bending the trunk more deeply. This is an attempt to place the motion closer to the centre of gravity through trunk bending when the muscle strength of the lower limbs is weak (Yu and Lim, 2007). Moreover, when standing up, the centre of gravity line in the trunk is placed behind the hip joint axis, thus forming a gradient moment behind the pelvis, and because dynamic stability is provided to the pelvis, passive stability is acquired through the ligaments (Levangie and Norkin, 2005).

Falling accidents, such as falling over and slipping, occur easily in elderly people due to physical changes, such as reduced balance, functional degeneration of the nervous system, reduced gait ability and weakened muscle strength. In terms of places in which falls can occur, research indicates that bathrooms are potentially the most dangerous place, followed by front doors, bedrooms, kitchens, living rooms and stairs, respectively (Park, 2004). When
${ }^{*}$ Corresponding author: Sang-Yeol Lee (iD http://orcid.org//0000-0003-4428-9101 Department of Physical Therapy, College of Science, Kyungsung University, 309, Suyeong-ro, Nam-gu, Busan 48434, Korea

Tel: +82-51-663-4873, Fax: +82-51-628-4870, E-mail: sjsh486@hanmail.net Received: July 29, 2016 / Accepted: September 27, 2016
This is an Open Access article distributed under the terms of the Creative Commons Attribution Non-Commercial License (http://creativecommons.org/licenses/by-nc/4.0/) which permits unrestricted non-commercial use, distribution, and reproduction in any medium, provided the original work is properly cited. 
standing up from sitting, the centre of gravity is switched from a stable condition to an unstable condition as the joints are bent, thereby requiring the coordination of trunk muscles (Baer and Ashburn, 1995). Consequently, weak elderly people and patients with musculoskeletal disorders have difficulty performing the motion of standing up without assistance (Mak et al., 2003). Even healthy elderly people are highly likely to fall forward while standing up from a sitting position because they more frequently use the hip joints than the knee. Thus, one study recommended that the elderly use an aid or a tool when standing up from a low chair with a seat height of $35 \mathrm{~cm}$ or below (Park et al., 2012).

The motion of standing up from sitting presents the highest risk of falls among the most frequently used motions in daily life, and bathrooms or toilets clearly top the list of spaces that cause falls. As with sitting on and standing up from a chair in daily life, sitting on and standing up from a toilet seat is also frequently performed by elderly people, pregnant women and disabled people. Thus, this study adjusted the angle and height of a toilet seat while subjects with consistent levels of muscle strength in the lower limbs stood up from the toilet seat after evacuation. By doing so, the study aimed to examine the effects of changes in the angle and height on movements and ground reaction forces in the feet.

\section{MATERIALS AND METHODS}

\section{Participants}

The subjects were 22 healthy male and female adults at DongEui University, who had normal ranges of motion necessary for the motion of standing up from sitting that is required in this study, and they understood the contents of this study and agreed to participate (Table 1).

The selection criteria for the subjects were as follows:

(1) Those who had neither problems with independent walking nor weakened muscles in the lower limbs and trunk.

(2) Those who neither complained of pain while performing the required motion nor had contractures in the restricted joints.

(3) Those who did not have a medical history of surgical or neu-

Table 1. Characteristics of study participants $(n=20)$

\begin{tabular}{lc}
\hline Variable & Value \\
\hline Gender, male:female & $6: 14$ \\
Age $(\mathrm{yr})$ & $20.10 \pm 0.71$ \\
Height $(\mathrm{cm})$ & $164.00 \pm 7.49$ \\
Weight $(\mathrm{kg})$ & $58.72 \pm 9.21$ \\
\hline
\end{tabular}

Values are presented as number or mean \pm standard deviation. rological diseases related to the musculoskeletal systems of the trunk and lower limbs.

(4) Those who agreed to participate in this study.

\section{Design}

The motion required in this study is similar to that of standing up from sitting on a chair, which is commonly performed in daily life. The subjects started from the position of sitting straight. They then placed their feet parallel to one another, let their entire soles touch the floor, bent both knees and maintained this position. In addition, they comfortably placed both hands on the knees so that the palms touched the knees. In this position, the subjects performed the motion of standing up from the toilet seat according to the measurer's signals.

\section{Exercise program}

The Tumble Forms Wedges $\left(10^{\circ}[8 \mathrm{~cm}], 15^{\circ}[15 \mathrm{~cm}]\right)$ of Sammons Preston (Warrenville, IL, USA) were placed on the toilet seat to create angles and heights at $0^{\circ}(43 \mathrm{~cm}), 10^{\circ}(51 \mathrm{~cm})$, and $15^{\circ}$ $(58 \mathrm{~cm})$. This experiment was conducted in a random sampling manner. After the subjects were instructed to look straight ahead, they had to repeat the required motion for each angle 3 times, taking a 2-min break between each repetition.

\section{Measurements and statistical analysis}

In this study, the experiment was conducted on a single force plate to examine movements and ground reaction forces in the feet while the subjects were standing up from sitting (BP600400, AMTI Co., Watertown, MA, USA), and data on vertical, forward-and-backward and side-to-side ground reaction forces were obtained. A one-way analysis of variance approach was used to compare the changes according to the three angles and heights. Fisher least significant difference post boc analysis was performed and the statistical significance level was set to 0.05 .

\section{RESULTS}

The subjects were 20 healthy male and female adults and their general characteristics were as follows: $20.10 \pm 0.71$ years of age, $164.00 \pm 7.49 \mathrm{~cm}$ in height and $58.75 \pm 9.21 \mathrm{~kg}$ on average.

Comparison of the side-to-side travel distances, according to the angles and heights when standing up: The side-to-side travel distances when the subjects stood up from sitting were 103.70 \pm 12.46 at $0^{\circ}(43 \mathrm{~cm}), 96.99 \pm 12.11$ at $10^{\circ}(51 \mathrm{~cm})$, and $99.12 \pm 12.00$ at $15^{\circ}(58 \mathrm{~cm})$. While a higher angle led to a corre- 
Table 2. Comparison of the angle and height on movements and ground reaction forces

\begin{tabular}{|c|c|c|c|c|c|}
\hline \multirow{2}{*}{ Variable } & \multicolumn{3}{|c|}{ Angle } & \multirow{2}{*}{$F$} & \multirow{2}{*}{$P$-value } \\
\hline & $0^{\circ}(43 \mathrm{~cm})$ & $10^{\circ}(51 \mathrm{~cm})$ & $15^{\circ}(58 \mathrm{~cm})$ & & \\
\hline Side-to-side & $103.70 \pm 60.18$ & $96.99 \pm 54.16$ & $99.12 \pm 55.20$ & 0.075 & 0.928 \\
\hline $\begin{array}{c}\text { Forward and } \\
\text { backward }\end{array}$ & $235.93 \pm 47.38$ & $194.16 \pm 36.12$ & $181.63 \pm 38.72$ & 9.604 & 0.000 \\
\hline $\begin{array}{l}\text { Ground reaction } \\
\text { forces }\end{array}$ & $1.08 \pm 0.10$ & $1.08 \pm 0.09$ & $1.07 \pm .098$ & 0.109 & 0.897 \\
\hline
\end{tabular}

Values are presented as mean \pm standard deviation.

sponding decline in the travel distance that indicates side-to-side swaying, this result was not statistically significant.

Comparison of the forward and backward travel distances, according to the angles and heights when standing up: The forward and backward travel distances when the subjects stood up from sitting were $235.93 \pm 10.60$ at $0^{\circ}(43 \mathrm{~cm}), 194.17 \pm 8.07$ at $10^{\circ}$ $(51 \mathrm{~cm})$, and $181.63 \pm 8.66$ at $15^{\circ}(58 \mathrm{~cm})$. A higher angle led to a corresponding decline in the travel distance that indicates forward and backward swaying, and this result was statistically significant.

Comparison of the ground reaction forces, according to the angles and height when standing up: The ground reaction forces when the subjects stood up from sitting were $1.09 \pm 0.02$ at $0^{\circ}$ (43 $\mathrm{cm}), 1.08 \pm 0.22$ at $10^{\circ}(51 \mathrm{~cm})$ and $1.07 \pm 0.21$ at $15^{\circ}(58 \mathrm{~cm})$. Thus, increases in the angle did not result in statistically significant differences in the ground reaction force (Table 2).

\section{DISCUSSION}

Some studies have reported that a higher toilet seat resulted in a corresponding shorter time to perform the motion of standing up, which subsequently reduced muscle activity. In light of this, the present study intended to examine whether changes in the angle and height of the toilet seat also led to changes in the ground reaction force in the legs, forward and backward sways and sideto-side sways. When the angle and height were adjusted at $0^{\circ}(43$ $\mathrm{cm}), 10^{\circ}(51 \mathrm{~cm})$, and $15^{\circ}(58 \mathrm{~cm})$, the travel distance of side-toside swaying did not exhibit statistically significant differences. This coincides with the result of a biodynamical analysis (Kim et al., 2006) on the motion of standing up performed by elderly and young people while their knee and hip joints were fixed at $90^{\circ}$. The condition of fixing knee and hip joints at $90^{\circ}$ was identical with that of fixing at $0^{\circ}(43 \mathrm{~cm})$ in the present study, in which no differences were observed in sideways travel distance between the elderly and young people. In fact, the side-to-side swaying when the subjects were extending their knees to stand up were not significant unless they had unbalanced left and right muscle strength in the quadriceps femoris.

Lee (1998) investigated how movement speeds while healthy individuals were standing up affected the largest ground reaction force, and reported that an increase in speed resulted in proportionate increases in all elements. By contrast, Kim et al. (2006) reported that while no statistically significant changes were shown in the total time for standing up and the range of motion of the hip and knee joints, there were differences in internal strategy. They also noted that there may have been some differences, including differences in kinematic variables, such as standing up by detaching the hips after excessively bending the upper body forward. The present study also showed no statistically significant differences in side-toside sways for the various angles and heights, but statistically significant differences in the forward and backward sways. This result corresponds to those of previous studies where the subjects showed large movements in the motion of bending the upper body forward to stand up by means of small forces. This is also associated with the result of a previous study (Son et al., 2012) that the strategy of bending the upper body further forward and placing the centre of gravity forward due to problems with muscle strength or when standing up from a low chair increases the incidence of falls due to increased instability, and thus maximum power should be increased and the sway of the centre of pressure should be reduced to prevent it (Son et al., 2012).

During standing up, increases in the height and angle of the toilet seat also led to corresponding declines in the ground reaction force, which were from 1.09 times the body weight to 1.08 times and 1.07 times. However, this result was not statistically significant. Kim et al. (2015) reported in their study that increases in the height and angle of the toilet seat resulted in corresponding declines in the activity of trunk and leg muscles. Therefore, we had predicted that increases in the height and angle of the toilet seat would also visibly decrease the ground reaction force. However, the present study showed that the height and angle of the toilet seat did not largely influence the reaction force according to the body weights of the subjects while they were positioning themselves upright in a space.

When only the height of the toilet seat is increased, short elderly patients can experience the discomfort of not being able to touch the floor with their feet, as well as reduced stability because the trunk is detached from the floor. To prevent this, a previous study (Kim et al., 2015) adjusted the angle of the toilet seat along with the height so that the subjects would be able to perform 
closed chain exercises with their soles placed on the floor. As changes in the angle and height of the toilet seat during standing up can affect backward and forward sways, adjusting the height and angle to suit each individual is likely to help prevent falls.

\section{CONFLICT OF INTEREST}

No potential conflict of interest relevant to this article was reported.

\section{REFERENCES}

Baer GD, Ashburn AM. Trunk movements in older subjects during sit-tostand. Arch Phys Med Rehabil 1995;76:844-849.

Barthelemy S, Salaun C, Bidaud P. Dynamic simulation and control of sitto-stand motion. In: Proceedings of the 9th International Conference on Climbing and Walking Robots and the Support Technologies for Mobile Machines; 2006 Sep 12-14; Brussels, Belgium. Paris: Laboratoire de Robotique de Paris; 2006.

Chamberlain MA, Munton J. Designing chairs for the disabled arthritic. Br J Rheumatol 1984;23:304-308.

Hwang SJ, Son JS, Kim JY, Kim HD, Kim YH, Lim DH, Kim YH. Analysis of Joint movements and changes of muscle length during STS (sit-tostand) at various sitting heights in the Korean elderly's daily life. J. Biomed Eng Res 2008;29:484-492.

Kim BJ, Lee SK, Lee JH, Kwon HY. The effects of lower limb and trunk muscle activation on seat angle and height during sit to stand and stand to sit. J Korean Soc Phys Med 2015;10:107-112.

Kim DH, Park SM, Jeon D, Sung DH. Kinetic and kinematic comparison of sit-to-stand movement between healthy young and elderly subjects. J Korean Acad Rehabil Med 2006;30:385-391.

Lee SH. Effect of speed of movement on maximum ground reaction force during the sit to stand transfer. Phys Ther Korea 1998:5:20-29.

Levangie PK, Norkin CC. Joint structure and function: a comprehensive analysis. 4th ed. Philadelphia: FA Davis; 2005.

Mak MK, Levin O, Mizrahi J, Hui-Chan CW. Joint torques during sit-tostand in healthy subjects and people with Parkinson's disease. Clin Biomech (Bristol, Avon) 2003;18:197-206.

Pai YC, Rogers MW. Speed variation and resultant joint torques during sit-to-stand. Arch Phys Med Rehabil 1991;72:881-885.

Park TJ, Jeong OC, Sun S, Seo KE, Yang SH. Differences in lower extremity coefficient of joint contribution for a sit-to-stand movement with change of chair height in able-bodied young and old women. Korean J Sports Sci 2012;21:1353-1364.

Park YH. Influence risk of falls in elders who live at home. J Korean Gerontol Nursing 2004;6:170-178.

Scholz JP, Reisman D, Schöner G. Effects of varying task constraints on solutions to joint coordination in a sit-to-stand task. Exp Brain Res 2001;141:485-500.

Son S, Park TJ, Kang YT, Seo, KE. Kinetic analysis of sit to stand movement with change of chair heights in able bodied 60s and 20s women. Korean J Sports Sci 2012:21:1249-1258.

Yu YJ, Lim BO. Kinematic analysis of rising from a chair in healthy and stroke subjects. Korean J Sport Biomech 2007;17:103-122. 